\title{
Effective interplay of donor and acceptor groups for optoelectronic properties tuning in Oligothiophene- Naphtalimide Assemblies
}

Matías J. Alonso-Navarro ${ }^{\mathrm{a}, \dagger \dagger}$, Alexandra Harbuzaru ${ }^{\mathrm{b} \dagger}$, Paula de Echegaray ${ }^{\mathrm{a}, \mathrm{q} \ddagger}$, Iratxe Arrechea-Marcos ${ }^{\mathrm{b} \ddagger}$, Albert-Harillo-Baños ${ }^{\mathrm{d}}$, Alejandro de la Peña ${ }^{\mathrm{a}, \mathrm{c}}$ M. Mar Ramos, ${ }^{\mathrm{c}} \mathrm{J}$. Teodomiro López Navarrete ${ }^{\mathrm{b}}$, Mariano Campoy-Quiles ${ }^{\mathrm{d}}$, Rocío Ponce Ortiz ${ }^{\mathrm{b} *}$, José L. Segura ${ }^{a *}$

${ }^{a}$ Department of Organic Chemistry, Complutense University of Madrid, Faculty of Chemistry, Madrid 28040, Spain.

${ }^{b}$ Department of Physical Chemistry, University of Málaga, Málaga, 29071, Spain.

${ }^{c}$ Chemical and Environmental Technology Department. Univ. Rey Juan Carlos, Móstoles, 28933, Spain.

${ }^{\mathrm{d} I n s t i t u t ~ d e ~ C i e n c i a ~ d e ~ M a t e r i a l s ~ d e ~ B a r c e l o n a ~(I C M A B-C S I C), ~} 08193$ Bellaterra, Spain

${ }^{\dagger}$ These authors contributed equally to this work

$\$$ These authors contributed equally to this work

\begin{abstract}
In this work, a series of naphthalimide fused thienopyrazine derivatives was designed, and their synthesis and characterization are reported herein. The interaction of this building block with a donor terthiophene fragment laterally substituted by a series of donor and acceptor constituents was analyzed in depth. This strategy was proven to efficiently modulate both the energy and topology of the frontier molecular orbitals involved in the charge transport mechanism. The interplay between the donor and acceptor strengths of the different units composing the materials structure is thus essential to efficiently modulate charge carriers and transport properties and to finely tune the optical and electronic structures of the presented organic semiconductors.
\end{abstract}

\section{Introduction}

Conjugated organic molecules are ideal semiconductors for the generation of low-cost electronics ${ }^{1-4}$ due to the combination of their tunable optical and electronic properties with their excellent mechanical flexibility and processing. Thus, they provide a good platform for a wide variety of applications such as organic field effect transistors 
(OFETs), ${ }^{5-7}$ organic thin-film transistors (OTFTs) ${ }^{8}$ organic light emitting diodes $(\mathrm{OLEDs})^{9,10}$ and organic solar cells (OSCs). ${ }^{11}$

Concerning OFETs, charge carrier mobility is one the most important device parameters for many of the targeted applications. In this respect, OFETs mobilities exceeding 10 $\mathrm{cm}^{2} \mathrm{~V}^{-1} \mathrm{~s}^{-1}$ have been already reported for several organic semiconductors. ${ }^{12-15}$ Nevertheless, these high mobility values have been mainly achieved for p-type organic semiconductors, in which holes are the charge carriers in the OFET channel. However, it is worth pointing out that n-channel OFETs, using n-type organic semiconductors that conduct electrons, are required for many electronic applications in order to make complementary metal oxide (CMOS)-like logic circuits in combination with the pchannel OFETs. ${ }^{16,17}$ In order to obtain n-type organic semiconductors it is necessary to synthesize $\pi$-conjugated electron deficient systems that allow the electron hopping in films providing semiconducting properties to the material. ${ }^{18}$ Among them, rylene imide derivatives have proven to be among the most efficient n-type organic semiconductors for their application in OFETs due to their great optical and electrochemical properties which can be tuned by chemical modifications. ${ }^{19-27}$

In this context, naphthalene-based imides have been extensively used within organic electronics due to its easy functionalization, tunable absorption spectrum, electron deficient core and low lying LUMO, stable radical anion and self-organization properties. ${ }^{24,28-30}$ Specially noteworthy is that n-type mobilities above $8 \mathrm{~cm}^{2} \mathrm{~V}^{-1} \mathrm{~s}^{-1}$ have been reported for single-crystal field-effect transistors based on naphthalene diimide derivatives. $^{31}$

In recent years, our groups have been developing new series of oligothiophenenaphthalimide semiconductors which combine donor and acceptor units in order to create ambipolar or n-type materials by tuning efficiently their frontier orbital levels and modifying their optical, electrochemical and electronic properties (Figure 1a). ${ }^{32-35}$ In the frame of this ongoing research, we report herein the synthesis of a family of terthiophenenaphthalimide assemblies (Figure 1b) in which the electronic energy levels, emission and absorption spectra, as well as the intermolecular stacking have been tuned effectively through chemical modification of the end groups located at terminal thiophene moieties in the oligothiophene-naphthalimide assemblies. The range of functionalities incorporated in the terthiophene-naphthalimide assemblies ranges from non-planar strong donor substituents such as triphenylamine, ${ }^{36-38}$ planar $\pi$-conjugated donor substituents such as pyrene moieties, ${ }^{39-41}$ rigid linear and bulky substituents such as triisopropylsilyl 
(TIPS) groups ${ }^{42-44}$ and strong electron accepting functions such as rhodanine ${ }^{45-47}$ and dicyanovinylene $\mathrm{e}^{48-50}$ that promote planarity and extended conjugation. All these substituents have been selected because of their different electronic and structural characteristics and because they have been previously used successfully in the functionalization of $\pi$-conjugated molecular organic materials with good charge transport properties.
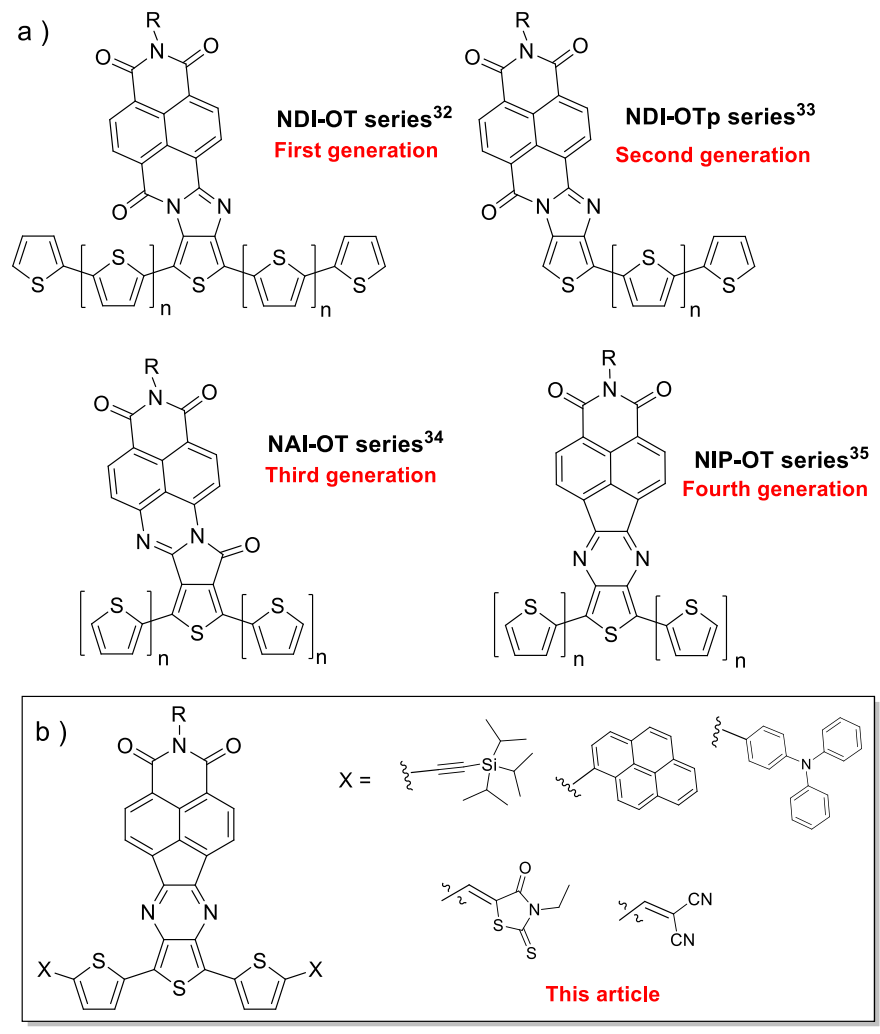

Figure 1 (a) Molecular structure of oligothiophene-naphthalimide assemblies synthesized in our groups with good performances in OFETs and (b) new oligothiophenenaphthalimide assemblies investigated in this article.

\section{Results and discussion}

The development of Donor (D)-acceptor (A) assemblies based on oligothiophene derivatives have received a great deal of attention due to the tunability of their electrochemical and photophysical properties, which have allowed their incorporation in OFETs showing ambipolar field-charge transport. ${ }^{51-57}$ Among them, oligothiophenenaphthalimide assemblies ${ }^{58}$ are particularly appealing because of the significance of naphthalimide in supramolecular chemistry and as air-stable n-type semiconductors. ${ }^{29,53}$, ${ }^{59}$ Thus, we have synthesized different series of oligothiophene-naphthalimide assemblies (Fig. 1a) with good performances in OFETs in which both the acceptor and donor 
moieties are directly conjugated through rigid heterocyclic linkers. ${ }^{33-35,60,61}$ It has been observed that the use of planar pyrazine moieties as heterocyclic conjugated linker in oligothiophene-naphthalimide assemblies avoid skeletal distortions thus allowing extended intramolecular $\pi$-conjugation and permitting close intermolecular $\pi$ - $\pi$ stacking, which promote good film crystallinity.

In this article, we have carried out the chemical modification of the base skeleton of these oligothiophene-naphthalimide assemblies connected by pyrazine linkers in order to further functionalize them with different moieties at terminal thiophene positions with the aim to tune the electronic energy levels, emission and absorption spectra, as well as the intermolecular stacking of the assemblies. The donor-acceptor systems can be classified into two well-defined groups. First, donor-acceptor-donor (D-A1-D) systems, in which there are electron donor systems on each side of the acceptor thienopyrazine moiety and, on the other hand, A2-D-A1-D-A2 systems, where the terminal positions of oligothiophene have been functionalized with strong electron acceptors. The synthetic route toward all the naphthalimide-fused thienopyrazine end-capped molecules reported in this work starts with 1,8-naphthalimide derivatives endowed with 1,2-diketone functionalities (NIDa, NIDb) previously described by our group. ${ }^{35,61,62}$

Suitably functionalized terthiophene-naphthalimide assemblies connected through pyrazine linkers have been obtained by condensing NIDa and/or NIDb with the corresponding diamines 1 or 5 (Schemes 1 and 2). Thus, reaction between NIDa and 5"dibromo-[2,2':5',2"-Terthiophene]-3',4'-diamine (1) allows obtaining an oligothiophenenaphthalimide assembly (NIPa3T-Br) functionalized with bromine groups at the terminal thiophene moieties in a good yield (Scheme 1). The synthesis of this derivative paves the way for the further functionalization of this D-A assembly through different CC coupling reactions including Stille or Sonogashira reactions. Thus, Stille cross-coupling reaction between NIPa3T-Br and trimethyl[2-[tris(1-methylethyl)silyl]ethynyl]stannane (2) afforded an assembly functionalized with rigid and bulky triisopropylsilyl (TIPS) moieties (NIPa3T-TIPS) (Scheme 1). Alternatively, Suzuki cross-coupling reactions between NIPa3T-Br and boronic acid 3 or boronate ester $\mathbf{4}$ have been used to functionalize the oligothiophene-napthalimide assemblies respectively with non-planar strong donor triarylamine moieties (NIPa3T-TA) and electron-rich and planar pyrene units (NIPa3T-Py, Scheme 1). 


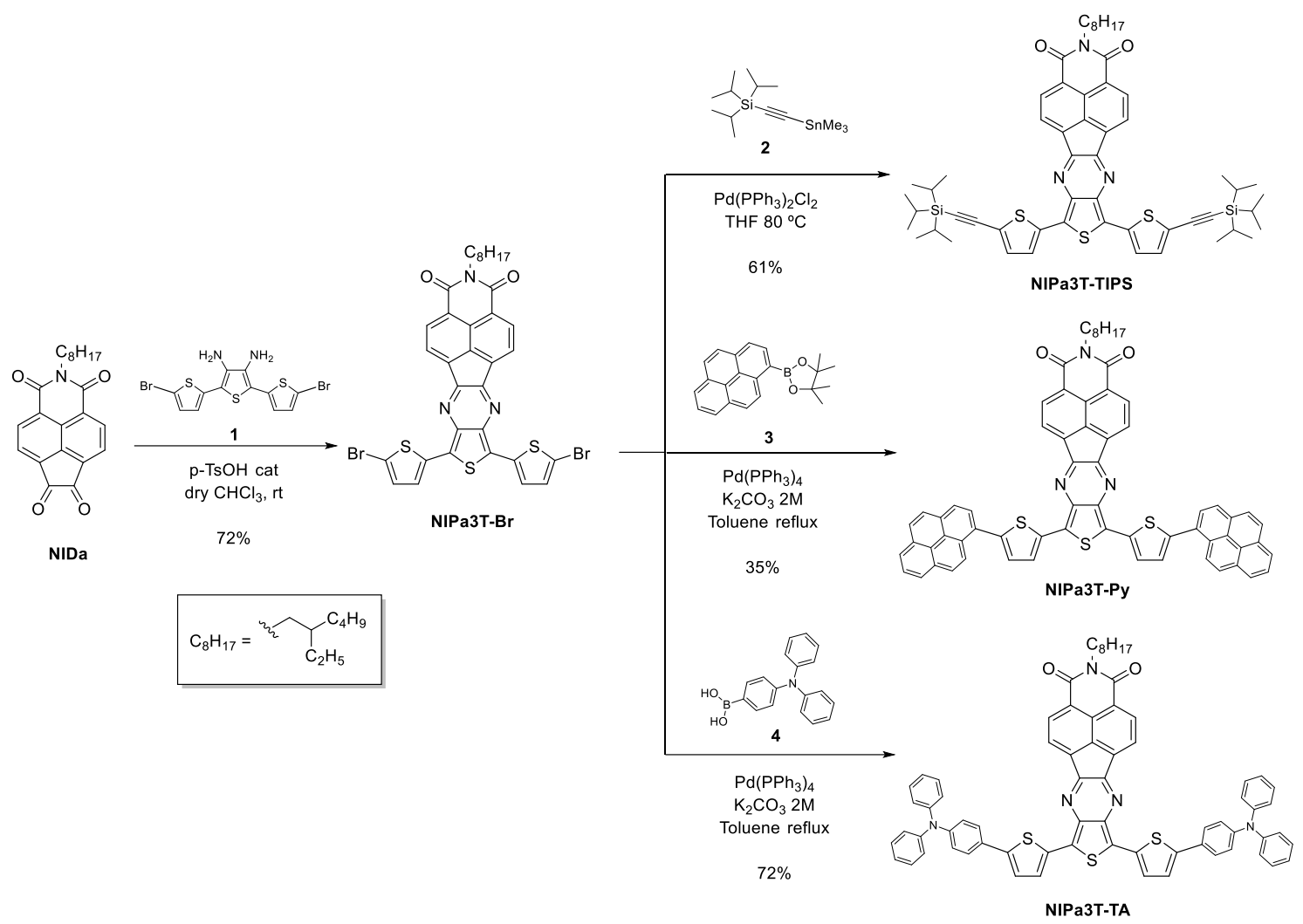

Scheme 1 Syntheses of the oligothiophene-naphthalimide assemblies functionalized with triisopropylsilyl (TIPS) moieties (NIPa3T-TIPS) and electron donor pyrene (NIPa3TPy) and triphenylamine (NIPa3T-TA) groups.

In order to obtain the A2-D-A1-D-A2 systems, NIPa3T or NIPb3T moieties were formylated upon treatment with phosphorus oxychloride and $\mathrm{N}, \mathrm{N}$-dimethylformamide to afford NIPa3T-CHO and NIPb3T-CHO respectively with yields higher than $85 \%$ (Scheme 2). Knoevenagel-like reactions ${ }^{63}$ from the formylated derivatives were carried out in order to obtain the target molecules. Thus, reaction with 3-ethyl-2-thioxo-4thiazolidinone (6) yielded the oligothiophene-naphthalimide assemblies endowed with rhodanine moieties (NIPa3T-Rd, NIPb3T-Rd) while treatment with malononitrile (7) afforded the parent systems NIPa3T-DCV and NIPb3T-DCV functionalized with dicyanovinylene groups (Scheme 2). 


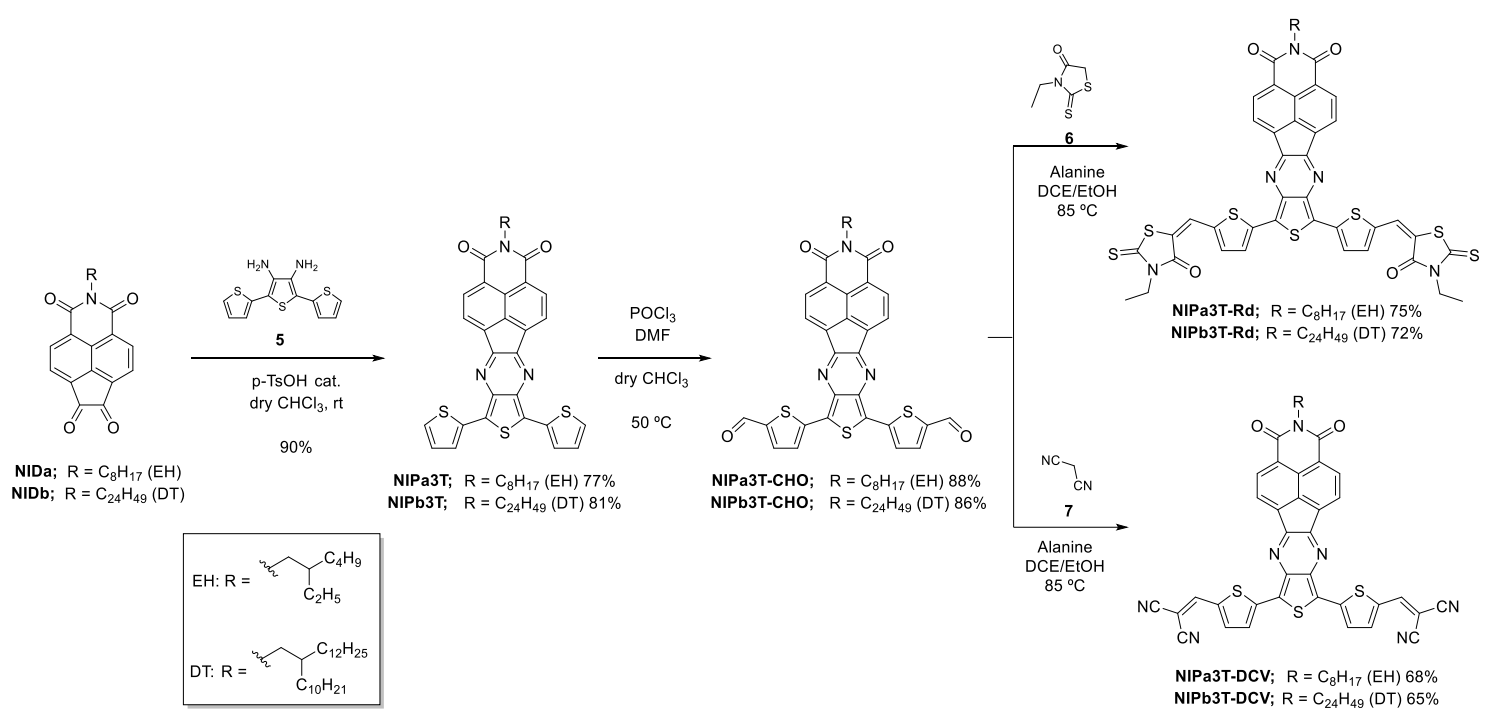

Scheme 2 Syntheses of the oligothiophene-naphthalimide assemblies functionalized with electron acceptor rhodanine (NIPa3T-Rd, NIPb3T-Rd) and dicyanovinylene (NIPa3TDCV, NIPb3T-DCV).

The presence of solubilizing alkyl chains at the imide nitrogen of the naphthalimide system allowed not only solid-state characterization methods but also ${ }^{1} \mathrm{H}-\mathrm{NMR}$ characterization in solution due to the acceptable solubility of all the intermediates and target compounds in deuterated solvents. In addition, ${ }^{13} \mathrm{C}-\mathrm{NMR}$ characterization of all the intermediates and most of the target compounds could be carried out except for those functionalized with dicyanovinylene or pyrene moieties which could not be clearly resolved due to their extended planar systems with limited solubility because of their tendency towards aggregation.

The analysis of the ${ }^{1} \mathrm{H}-\mathrm{RMN}$ spectra (Figures S1-S4) revealed well-resolved patterns for all the novel assemblies. In comparison with the dibrominated assembly (NIPa3T-Br, Scheme 1), the D-A1-D systems (NIPa3T-TIPS, NIPa3T-Py, NIPa3T-TA) do not show significant differences in the signals corresponding to the naphthalimide moieties in the region between 8.60 and $7.50 \mathrm{ppm}$ while that corresponding to the oligothiophene systems (7.80-6.50 ppm) are only slightly shifted after substitution. Thus, for NIPa3TTA, the signals corresponding to the oligothiophene moiety are shielded in comparison with that of NIPa3T-Br due to the strong electron donor behavior of the triarylamine. In the cases of NIPa3T-TIPS and NIPa3T-Py, the oligothiophene protons are quite deshielded compared with the starting material due to the extended conjugation provided by the TIPS or pyrene units. 
In the case of A2-D-A1-D-A2 systems, also well-resolved patterns for all the novel assemblies (Figures S5-S12) were observed. The characteristic signal of the hydrogen from the vinylene group appears at around $7.20 \mathrm{ppm}$ for the rhodanine derivative and around $7.05 \mathrm{ppm}$ for the dicyanovinylene-substituted analogue as a singlet between the characteristic signals of the 1,8-naphthalimide (8.20-7.30 ppm) and thiophene protons (7.00-6.50 ppm). For these systems, there is a shielding effect in the signals corresponding to both, 1,8-naphthalimide and oligothiophene. For the derivatives endowed with shorter 2-ethylhexyl chains at the imide nitrogens, the target molecules had to be characterized in deuterated tetrachloroethane or dimethyl sulfoxide, due to their lower solubility in deuterated chloroform. As depicted in the supporting information (figures S13, S14), temperature dependent NMR experiments performed for NIPa3T-Rd and NIPa3T-DCV show significant aggregation-induced shifts in the ${ }^{1} \mathrm{H}-\mathrm{NMR}$ signals.

The ${ }^{13} \mathrm{C}-\mathrm{NMR}$ spectra for D-A1-D systems are quite similar for all of them; the signals at the down-field zone up to $160 \mathrm{ppm}$ correspond to the imide carbons while between 155 and $120 \mathrm{ppm}$ there are all sp2 carbon signals, including those corresponding to the triarylamine substituents. On the other hand, the signals at the high-field zone correspond to the alkyl chains and the ethynyltriisopropyl carbons. In addition, for the assembly endowed with rhodanine moieties, the characteristic signal of the $\mathrm{C}=\mathrm{S}$ group can be identified at $190 \mathrm{ppm}$.

In the IR spectra of all the novel assemblies, it can be observed the diagnostic stretching bands corresponding to the imide group centered around $1700 \mathrm{~cm}^{-1}$ and the characteristic ring stretch of pyrazine moiety centered around $1600 \mathrm{~cm}^{-1}$. A clear band at $2220 \mathrm{~cm}^{-1}$ corresponding to the characteristic $\mathrm{C} \equiv \mathrm{N}$ tension is observed for the dicyanomethylene derivatives while, for the rhodanine moieties, a $\mathrm{C}=\mathrm{S}$ tension around $1250 \mathrm{~cm}^{-1}$ can be clearly identified. Finally, further evidence concerning the structure proposed for the novel assemblies is obtained by the analysis of the exact mass obtained by mass spectrometry which provided mass values which are in accordance with the expected ones (Figures S36-S47).

\section{Molecular structures and packing}

The optimization of the lowest energy molecular structures of the studied semiconductors shows, as indicated in Figures 2 and S48, a completely planar skeleton for NIP3T. This unit and the complete conjugated skeleton remain planar upon introduction of non-bulky electrowithdrawing substituents, both rhodanine and dicyanovinylene groups. On the 
contrary, when bulkier pyrene and triphenylamine groups are used as substituents in the NIP3T core, these units adopt a configuration, which is not coplanar with the naphthalimide central unit.
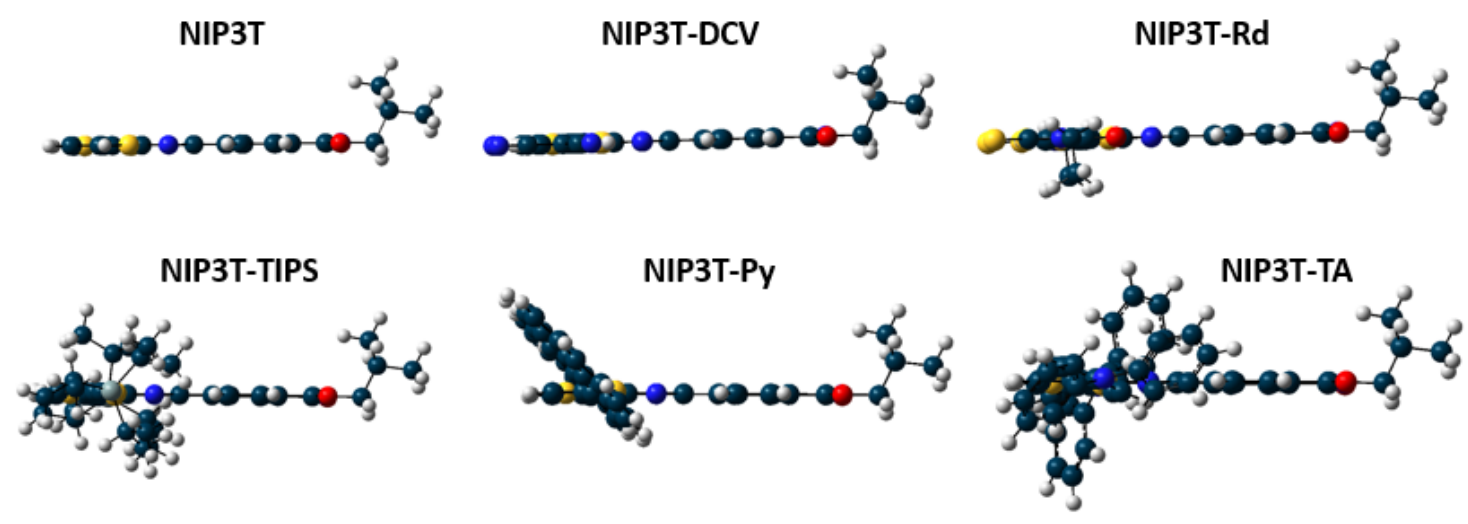

Figure 2 DFT/B3LYP/6-31G** optimized molecular structures for the semiconductors under study.

FT-Raman spectra were thus recorded to analyze the effect of the lateral substituents on $\pi$-conjugation and molecular properties, and the data is shown in Figure 3 and Figure S57. For this end, we make use of the ECC theory, ${ }^{64,}{ }^{65}$ which has been widely probed to efficiently account for the degree of conjugation of molecular materials in a qualitative way, ${ }^{66}$ and has been previously applied to naphthalene-modified oligothiophenes. ${ }^{67}$

Considering the Raman spectra in Figure 3 and the selected eingenvectors in Figure S58, the most intense Raman vibrations of NIPa3T, NIPa3T-DCV and NIPa3T-Rd are ascribed to the collective totally-symmetric $v(\mathrm{C}=\mathrm{C})$ vibration mode of the oligothiophene fragment, whose position can account for the molecular $\pi$-conjugation extent. This Raman vibration appears at $1449 \mathrm{~cm}^{-1}$ in NIPa3T and greatly downshifts upon inclusion of electrowithdrawing groups, being recorded at $1425 \mathrm{~cm}^{-1}$ in NIPa3T-DCV and 1416 $\mathrm{cm}^{-1}$ in NIPa3T-Rd. This remarkable downshift, up to $33 \mathrm{~cm}^{-1}$ in NIPa3T-Rd, indicates an effective conjugation extension by the insertion of electron-withdrawing groups.

On the contrary, the position of the terthiophene $v(C=C)$ symmetric vibration suffers less pronounced changes, up to $10 \mathrm{~cm}^{-1}$ shifts, in NIPa3T-TIPS, NIPa3T-Py and NIPa3TTA (Figure S57). This is probably due to the loss of planarity of the conjugated skeleton 
upon introduction of the lateral electron-donating groups, which interferes with the $\pi$ conjugation extension.

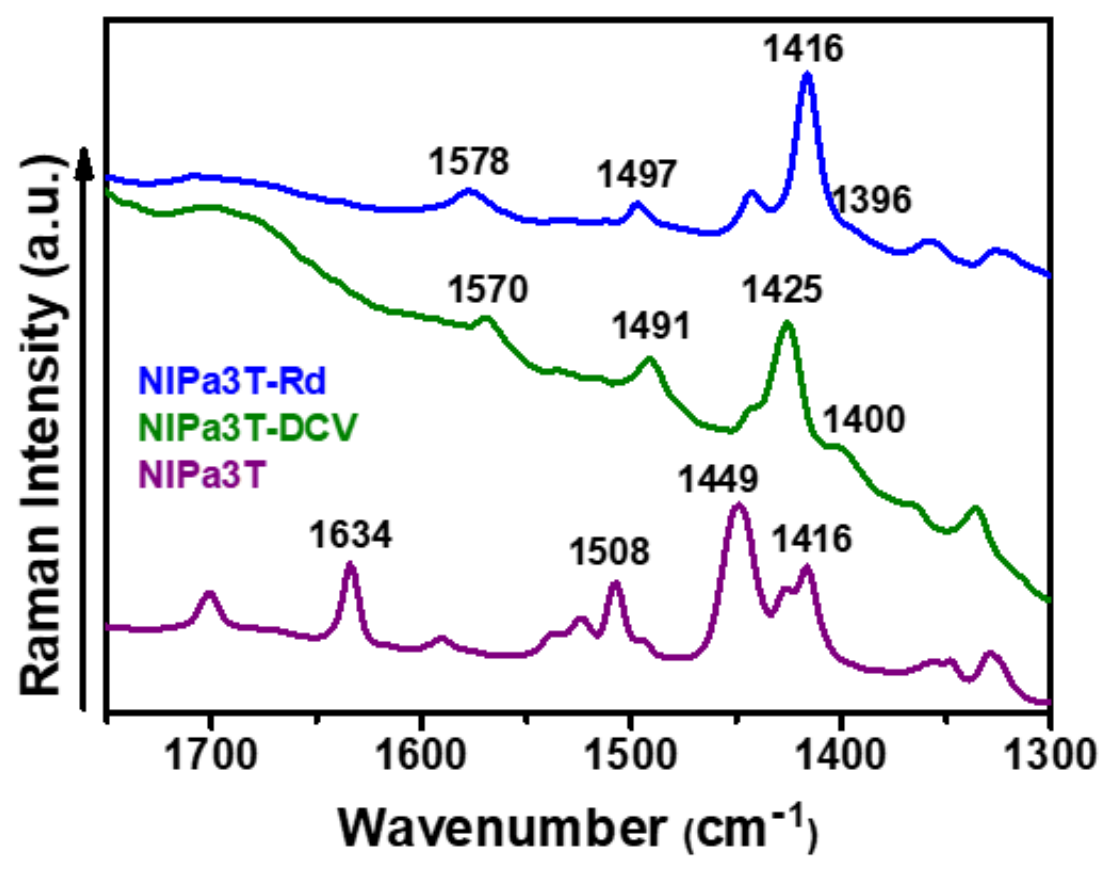

Figure 3. FT-Raman spectra $(\lambda=1064 \mathrm{~nm})$ of NIPa3T, NIPa3T-Rd and NIPa3T-DCV derivatives as bulk materials.

In addition, these different molecular geometries and combination of donor and acceptor groups induce different molecular dipole moments and geometrical restrictions that also influence solid state packing. ${ }^{32,34,60}$ Regarding the calculated molecular dipole moments, as shown in Table 1, they gradually decrease as the electron-rich character of the lateral substituents is enhanced. Thus, in NIPa3T-DCV and NIPa3T-Rd, the calculated dipole moments are 3.65 and 1.09 Debye, respectively, substantially lower than those of the rest of studied compounds, which are around 4.5-4.7 Debye (Table 1).

Thus, we theoretically predicted, at the DFT/wB97XD/6-31G* level, the formation of dimeric structures for the different semiconducting systems (Figure S55). The wB97XD functional was used in this case instead of the B3LYP level, because it has an empirical dispersion correction term, proposed by Grimme, that accurately predict $\pi-\pi$ stacking interactions. ${ }^{68}$ As shown in Table 1, while for NIPa3T both the antiparallel and parallel configuration are quasi isoenergetic, the parallel configuration is predicted to be the most stable one for the laterally substituted derivatives. 
In the case of NIPa3T-DCV and NIPa3T-Rd, the most stable parallel configuration respect to NIPa3T (antiparallel, Figure S55) can be understood in terms of molecular dipole moments. The interplay between the electron withdrawing strengths of the electron-rich lateral groups and the NIP unit induce molecules with low dipole moments. On the contrary, the parallel configuration of NIPa3T-Py, with a molecular dipole moment comparable to that of NIPa3T, is promoted by the formation of cooperative and close $\pi-\pi$ interactions between the pyrene groups (Table 1 ).

Table 1. DFT/wB97XD/6-31G* relative energy between parallel and antiparallel model of dimeric structures of the studied semiconductors. The less energetic configuration for each molecule is taken as reference, and thus it has been assigned a zero value. Inset: DFT/wB97XD/6-31G* optimized geometry for NIPa3T-Py dimeric model. The $\pi-\pi$ interactions are shown in the table.

\begin{tabular}{|c|c|c|c|c|c|c|}
\hline \multirow{2}{*}{ Molecules } & \multicolumn{2}{|c|}{$\begin{array}{c}\text { Relative Energy } \\
\text { (Kcal/mol) }\end{array}$} & \multirow[b]{2}{*}{ Conformers } & \multirow[b]{2}{*}{$\begin{array}{c}\text { Lower } \pi-\pi \\
\text { Distance }(\AA)\end{array}$} & \multirow[b]{2}{*}{$\mu$ (Debye) } & \\
\hline & Parallel & Antiparallel & & & & \\
\hline NIPa3T & 2,3 & 0 & Antiparallel & 3.39 & 4.43 & \\
\hline NIPa3T-Py & 0 & 19,67 & Parallel & 3.31 & 4.66 & \\
\hline NIPa3T-DCV & 0 & 7,29 & Parallel & 3.36 & 3.65 & \\
\hline NIPa3T-Rd & 0 & 15,45 & Parallel & 3.31 & 1.09 & \\
\hline
\end{tabular}

\section{Optical and electrochemical properties}

Figure 4 and Figures S59-S68 show the absorption spectra of the studied molecules and Tables 2 and S1 summarize the experimental and theoretical TD-DFT predicted results, respectively.

NIP3T is considered in this study as the main building block, common to all the studied systems, and it presents a simple absorption spectra profile with two main bands, being the lowest energy absorption band theoretically ascribed to the HOMO-LUMO transition. Thus, as indicated by the frontier molecular orbital topologies shown in Figure 5, this electronic transition entails a clear intramolecular charge transfer character, from the 
more electron-rich part of the semiconductor, the terthiophene counterpart, to the more electron deficient unit, the naphthalimide group.
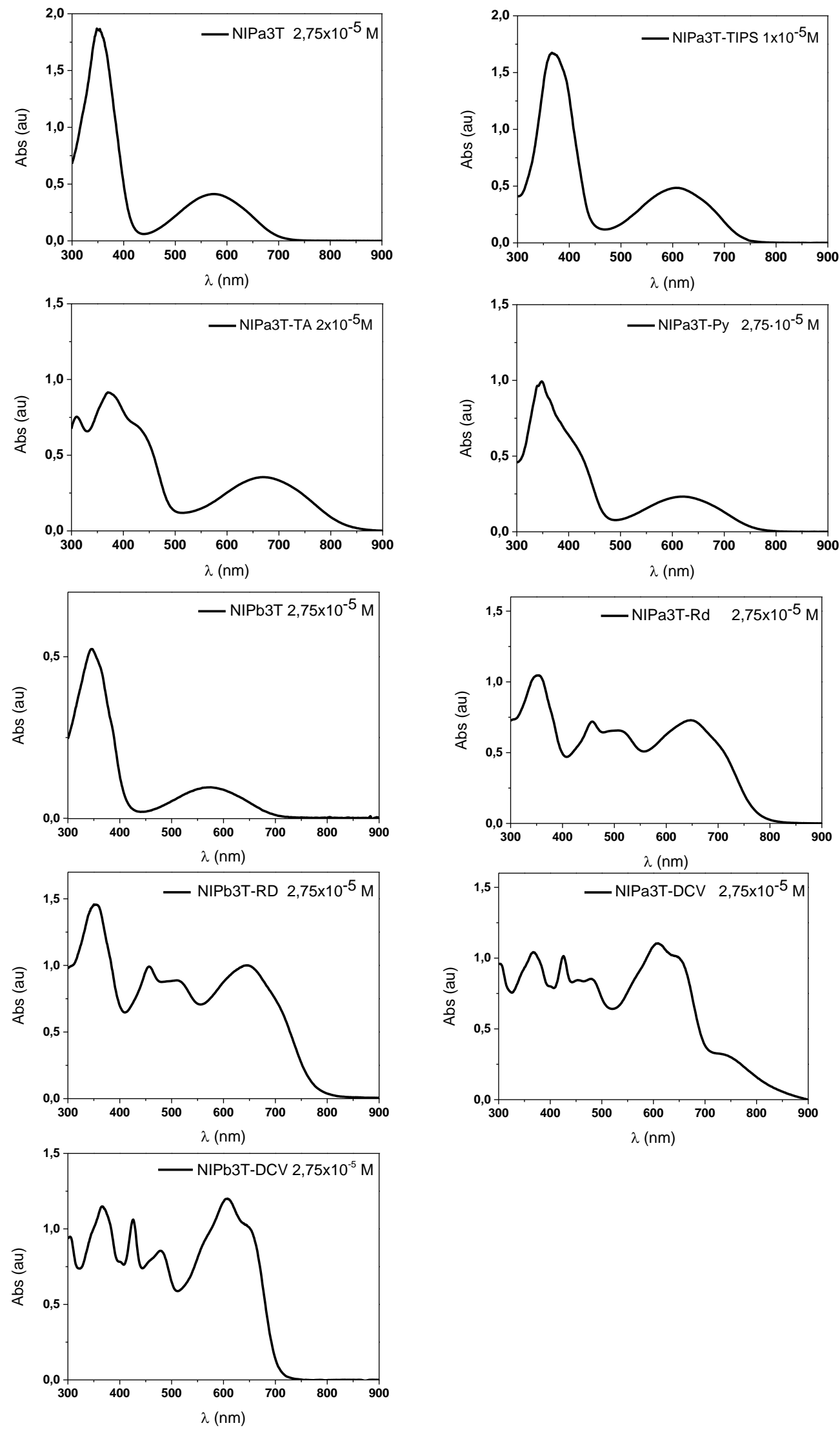
Figure 4 UV-Vis absorption spectra of the NIP3T derivatives recorded in chloroform.

A similar scenario is found for compounds NIPa3T-TA, NIPa3T-TIPS and NIPa3TPy, where the lateral substitution of the terthiophene fragment with electron-rich groups redshifts and accentuates the charge transfer character of the lowest energy absorption. As can be seen experimentally by the $\lambda_{\text {abs }}{ }^{\text {ons }}$ and theoretically by $\mathrm{E}_{\mathrm{H}-\mathrm{L}}$ in Table 2 and $\mathrm{S} 1$, respectively, the HOMO-LUMO energy gap gradually decreases as the electron-rich character of the lateral substituents is enhanced. Thus, the energy gap increases in the following direction: NIPa3T-TA $(1.49 \mathrm{eV})<$ NIPa3T-Py $(1.63 \mathrm{eV})<$ NIPa3T $(1.77 \mathrm{eV})$ $\approx$ NIPa3T-TIPS $(1.79 \mathrm{eV})$. This decrease in the HOMO-LUMO gap is also predicted theoretically as shown in Figure S50. Note that in these systems, the gap reduction is basically due to a destabilization of the HOMO orbital, without noticeable variation of the LUMO energy level. This is due to the spatially separated frontier molecular orbitals (Figure 5 and S49), which permits selective fine tuning of either the HOMO or the LUMO energy levels.

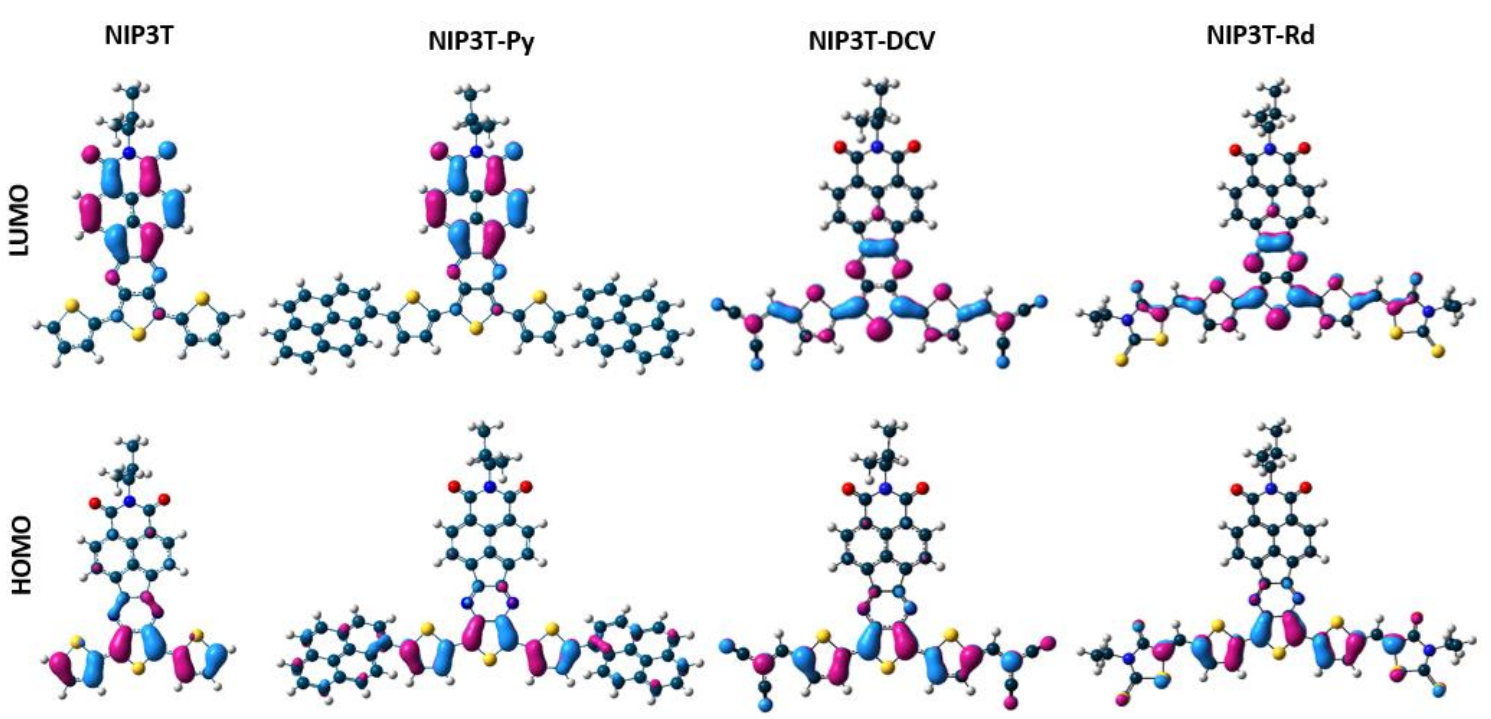

Figure 5 DFT/B3LYP/6-31G** molecular orbital topologies of NIP3T, NIP3T-Py, NIP3T-DCV and NIP3T-Rd.

On the contrary, the absorption spectra profile of the semiconductors laterally substituted with electron deficient groups, namely rhodanine and dicyanovinylene groups, is more complicated, with the presence of a vast number of electronic transitions (Figure 4 and Figures S65-S68). The introduction of electron deficient groups in the terminal position 
of the thiophenes allows the formation of fully conjugated materials with absorption over the whole visible spectrum. In general, the lengthening of the branched alkyl chains has small impact on the absorption spectra. However, although the two dicyanovinylene derivatives exhibit very similar UV-vis absorption profiles, the less soluble NIPa3TDCV derivative shows an additional band at around $760 \mathrm{~nm}$. This new band can be rationalized in terms of the formation of supramolecular aggregates. This particular behavior of the dicyanovinylene derivatives in the concentration range explored may be due to their lower solubility in comparison with the other NIP-3T derivatives. A dilution experiment has been carried out (figure S15) in order to confirm this aggregation behavior of NIPa3T-DCV. Thus, this new band assigned to supramolecular aggregates disappears when the solution is diluted enough. TD-DFT calculations (Table S1) predict the most intense electronic transition to be a one electron excitation from the HOMO to the LUMO; however, in this case the appearance of vibronic structure indicates the absence of intramolecular charge transfer in this electronic transition (see calculated transition dipole moments in Figure S56). This is corroborated by the molecular orbital topologies, which indicate that both HOMO and LUMO are delocalized over the laterally substituted terthiophene unit (Figure 5). The energy gaps, in this case, are calculated from the absorption onset as 1.60 and $1.38 \mathrm{eV}$ for NIP3T-Rd and NIP3T-DCV, respectively. The decrease respect to the parent compound NIP3T is related to a stabilization of both HOMO and LUMO energy levels, as shown in Figure S51.

Table 2. ${ }^{\text {a }}$ Absorption measurement in $\mathrm{CHCl}_{3}$ solution, ${ }^{\mathrm{b}}$ absorption maxima in solution, ${ }^{\mathrm{c}}$ absorption band for the onset wavelenght, ${ }^{\mathrm{d}}$ molar absorption coefficient to the referred wavelength, e energy band gap derived from the low-energy absorption edge using the equation $\mathbf{E}_{\mathbf{g}}{ }^{\text {opt }}=1240 / \lambda_{\text {onset }}$.

\begin{tabular}{|c|c|c|c|c|c|c|c|}
\hline & & \multicolumn{6}{|c|}{ UV-vis ${ }^{a}$} \\
\hline & $\begin{array}{c}{[C]} \\
(\mu \mathrm{M})\end{array}$ & $\begin{array}{c}\lambda_{\max }{ }^{b} \\
(\mathrm{~nm})\end{array}$ & $\begin{array}{c}\varepsilon_{\lambda \max }{ }^{d} \\
\left(M^{-1} \cdot \mathrm{cm}^{-1}\right)\end{array}$ & $\begin{array}{c}\lambda_{\varepsilon}^{c} \\
(n m)\end{array}$ & $\begin{array}{c}\varepsilon_{\lambda \varepsilon}{ }^{d} \\
\left(\mathrm{M}^{-1 .} \mathrm{cm}^{-1}\right)\end{array}$ & $\begin{array}{l}\lambda_{\text {onset }} \\
(\mathrm{nm})\end{array}$ & $\begin{array}{c}E_{\mathrm{g}}{ }^{o p t, ~} \mathrm{e} \\
(\mathrm{eV})\end{array}$ \\
\hline NIPa3T-TIPS & 0.100 & 349 & 167000 & 576 & 48000 & 689 & 1.79 \\
\hline NIPa3T-Py & 0.275 & 348 & 36000 & 620 & 8360 & 760 & 1.63 \\
\hline NIPa3T-TA & 0.200 & 370 & 45500 & 671 & 17500 & 831 & 1.49 \\
\hline NIPa3T & 0.275 & 348 & 68000 & 574 & 14910 & 698 & 1.77 \\
\hline NIPa3T-Rd & 0.275 & 353 & 38180 & 712 & 17820 & 774 & 1.60 \\
\hline NIPa3T-DCV & 0.275 & 609 & 40360 & 735 & 11640 & 899 & 1.38 \\
\hline NIPb3T & 0.275 & 346 & 18910 & 572 & 3636 & 694 & 1.79 \\
\hline NIPb3T-Rd & 0.275 & 354 & 53450 & 703 & 26910 & 768 & 1.61 \\
\hline NIPb3T-DCV & 0.275 & 607 & 43270 & 650 & 36730 & 704 & 1.76 \\
\hline
\end{tabular}


Cyclic voltammetries were carried out in an inert atmosphere in an electrochemical workstation at a scan rate of $200 \mathrm{mV} \cdot \mathrm{s}^{-1}$ at $20{ }^{\circ} \mathrm{C}$ using tetrabutylammonium

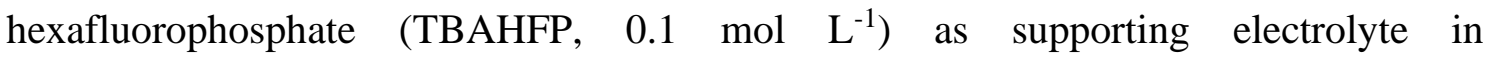
dichloromethane and the data are compiled in Table 3.

Table 3. ${ }^{a}$ Cyclic voltammetry recorded in $\mathrm{DCM} \mathrm{TBAPF}_{6}(0.1 \mathrm{M})$ at a scan rate of $0.2 \mathrm{~V} / \mathrm{s}$ using $\mathrm{Pt}$ as working and the counter electrode, and $\mathrm{Fc} / \mathrm{Fc}+$ as reference. ${ }^{\mathrm{b}}$ Estimated from $\mathrm{E}_{\mathrm{LUMO}}=-5.1 \mathrm{eV}-\mathrm{E}^{1 / 2} /$ redI. $^{\mathrm{c}}{ }^{\mathrm{E}}$ stimated from $\mathrm{E}_{\mathrm{HOMO}}=-5.1 \mathrm{eV}-\mathrm{E}^{1 / 2} /{ }_{\mathrm{oxI}}{ }^{\mathrm{d}}$ Half wave potential of the reversible wave. ${ }^{\mathrm{e}}$ Anodic peak potential of the irreversible wave.

\begin{tabular}{|c|c|c|c|c|c|c|c|c|}
\hline & \multicolumn{8}{|c|}{ Cyclic voltammetry $^{\mathrm{a}}$} \\
\hline & $\begin{array}{l}E_{\text {oxl }} \\
\text { (V) }\end{array}$ & $\begin{array}{c}E^{1 / 2}{ }_{\text {oxII }} \\
\text { (V) }\end{array}$ & $\begin{array}{c}E^{1 / 2} \text { redl } \\
\text { (V) }\end{array}$ & $\begin{array}{c}E^{1 / 2} \text { redll } \\
\text { (V) }\end{array}$ & $\begin{array}{c}E^{1 / 2}{ }_{\text {redIIII }} \\
\text { (V) }\end{array}$ & $\begin{array}{c}E_{\text {номо }}{ }^{c} \\
(\mathrm{eV})\end{array}$ & $\begin{array}{c}\text { ELUMo }^{b} \\
(\mathrm{eV})\end{array}$ & $\begin{array}{c}\mathbf{E}_{\text {gap }}{ }^{\text {elec }} \\
(\mathbf{e V})\end{array}$ \\
\hline NIPa3T-TIPS & $0.66^{d}$ & - & -1.34 & -1.69 & - & -5.76 & -3.76 & 2.00 \\
\hline NIPa3T-Py & $0.42^{\mathrm{e}}$ & - & -1.34 & -1.68 & - & -5.52 & -3.76 & 1.76 \\
\hline NIPa3T-TA & $0.29^{d}$ & 0.51 & -1.16 & -1.47 & - & -5.39 & -3.94 & 1.45 \\
\hline NIPa3T & $0.50^{\mathrm{e}}$ & - & -1.30 & -1.81 & - & -5.60 & -3.80 & 1.80 \\
\hline NIPa3T-Rd & $0.57^{\mathrm{e}}$ & 0.95 & -1.22 & -1.37 & -1.70 & -5.67 & -3.88 & 1.79 \\
\hline NIPa3T-DCV & $0.93^{d}$ & - & -1.03 & -1.31 & -1.72 & -6.03 & -4.07 & 1.96 \\
\hline NIPb3T & $0.48^{\mathrm{e}}$ & - & -1.34 & -1.74 & - & -5.61 & -3.71 & 1.90 \\
\hline NIPb3T-Rd & $0.60^{\mathrm{e}}$ & - & -1.24 & -1.36 & -1.70 & -5.76 & -3.86 & 1.90 \\
\hline NIPb3T-DCV & $0.89^{d}$ & - & -1.07 & -1.39 & -1.77 & -5.99 & -4.01 & 1.98 \\
\hline
\end{tabular}

Both reversible oxidation and reduction processes are recorded for all the semiconductors (Figures S69-S75). Due to the strong electron withdrawing effect of the dicyanovinylene groups, only one oxidation process is observed for both assemblies, NIPa3T-DCV and NIPb3T-DCV, and this process appear very close to the solvent/electrolyte window (figures S76 and S77). On the contrary, NIPa3T-Rd is able to undergo multiple reversible oxidation and reduction processes, due to largely extended conjugation as indicated by Raman spectroscopy (vide supra).

\section{Charged species study by Spectroelectrochemistry}

In this section, we aim to analyze the structure and stability of the charge carriers present in the electron transport process. Considering the different LUMO topologies induced by the lateral substitution of the terthiophene fragment (Figure 5), a different delocalization of the injected electrons over the $\pi$-conjugated structure must be expected during the charge transport process for the different analyzed molecules. 
Figures 6 and S79-S82 show the evolution of the UV/Vis/NIR spectra of the studied semiconductors obtained by progressive spectroelectrochemical reduction of low concentration solutions in presence of high excess of supporting electrolyte. Two different behaviors are found depending on the nature of the lateral substituents. Thus, when the oligothiophene fragment is either unsubstituted or connected to electron-rich units a similar spectral profile evolution is recorded, the same applying when substituted with electron-deficient units.
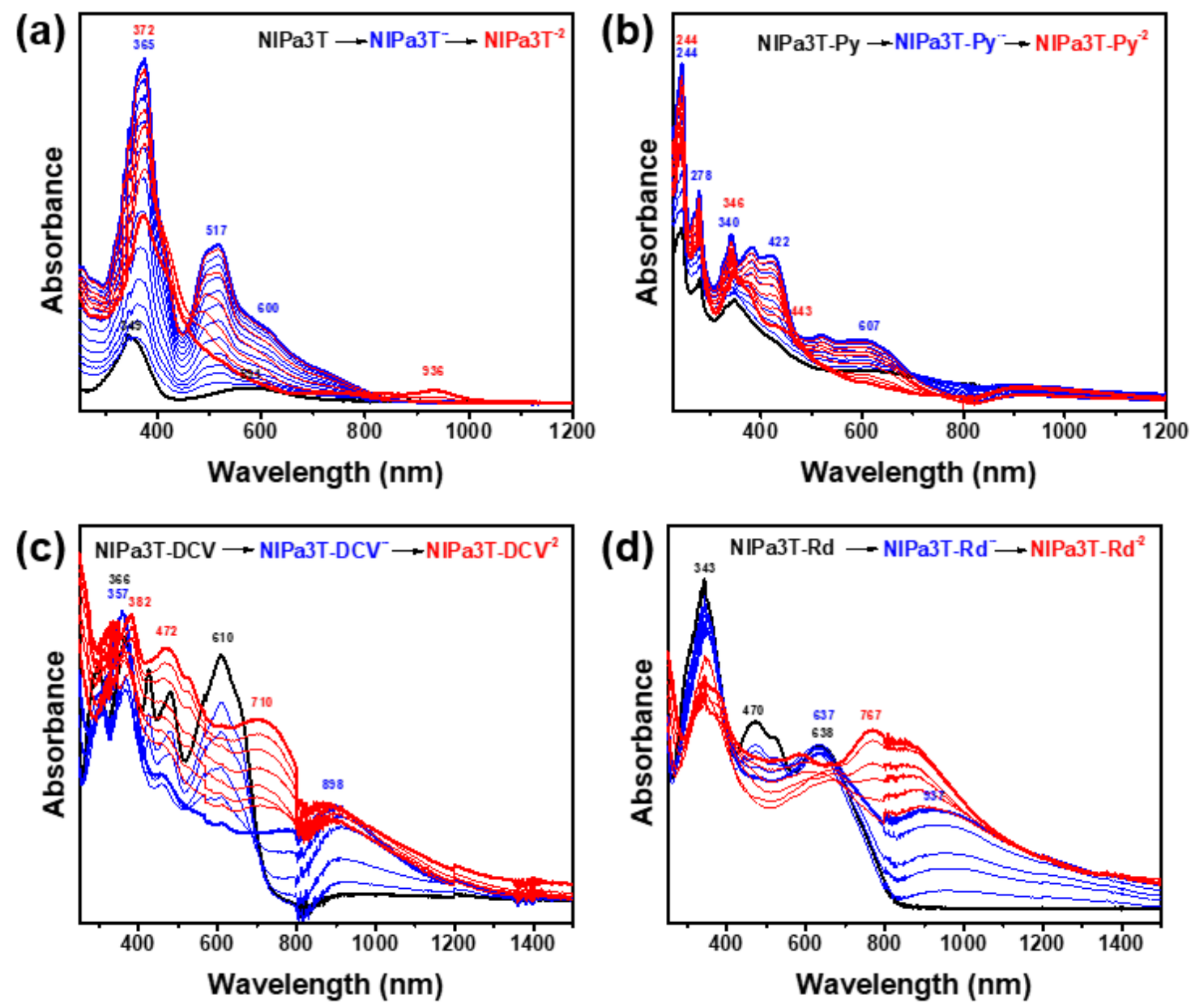

Figure 6. UV-Vis-NIR absorption spectra recorded by electrochemical reduction of (a) NIPa3T, (b) NIPa3T-Py, (c) NIPa3T-DCV and (d) NIPa3T-Rd in dichloromethane in presence of $\mathrm{Bu}_{4} \mathrm{NBF}_{4}$ as supporting electrolyte within an OTTLE cell. 
Therefore, for NIPa3T and NIPa3T-Py the UV-Vis absorption spectra of the neutral species (black curve) progressively evolve to a series of absorption bands recorded at 365 , 517 and $600 \mathrm{~nm}$ (blue curve) in the case of NIPa3T, which are ascribed to the formation of radical anion species (see comparison with theoretical results in Figure S79). Further electrochemical reduction provokes the vanishing of this spectral profile and the appearance of two new absorption peaks, one centered at ca 372 and a redshifted band at $936 \mathrm{~nm}$. A similar scenario has been previously observed upon chemical reduction of naphthalenediimide derivatives, ${ }^{69}$ therefore indicating that in NIPa3T and NIPa3T-Py the injected negative charge is mainly stabilized over the naphthaleneimide fragment, as expected considering the LUMO topologies in Figure 5. DFT calculations of NIPa3T-Py charged species indicate the stabilization of basically the totality of the injected charge on the naphthaleneimide subunit in the radical anion, while around $65 \%$ of the injected charge is stabilized by the NIP unit in the dianion species. Note that the pyrene lateral substituents, albeit being considered an electron-rich group, help in the stabilization of the injected negative charge for the dianion, hosting around $30 \%$ of the charge (Figure S52 and S53).

In marked contrast, NIPa3T-DCV and NIPa3T-Rd, where the terthiophene subunit is laterally substituted with electron-deficient groups show an evolution of their UV/Vis/NIR spectra upon electron injection that resemble those of electron-deficient oligothiophene materials. ${ }^{70}$ As an example, in the case NIPa3T-Rd, two bands appear at 761 and $884 \mathrm{~nm}$ upon one electron reduction. Further increase of the applied potential is translated in a decrease of these bands while increasing a new absorption at higher energies, that can be ascribed to the dianion species. In this case, the lateral electronwithdrawing groups are the ones bearing the majority of the injected charge (around 70\%, 
Figures S52 and S53), which is stabilized through the terthiophene skeleton as indicated in the LUMO orbital topology.

\section{Electrical characterization}

In order to evaluate the charge-transport characteristics of the studied semiconductors, field effect transistors in a top-contact/bottom-gate architecture were fabricated by vapor deposition of the semiconductor thin films onto SAM-treated substrates (both octadecyltrichlorosilane and hexamethyldisilazane reactants were used for the superficial treatment of the $\mathrm{SiO}_{2}$ dielectric layer). After semiconductors deposition, gold electrodes were patterned by using shadow masks with various predefined channel lengths and widths. Performance parameters were extracted from the I-V response plots, recorded at vacuum conditions, in the saturation regime using the conventional transistor formalisms, and are summarized in Table 4.

Table 4. OFET electrical data for vapor deposited films of the indicated semiconductors measured in vacuum. Average field-effect mobilities are shown.

\begin{tabular}{|cccccccc|}
\hline Semiconductor & $\begin{array}{c}\text { Deposition } \\
\text { Conditions }\end{array}$ & $\mu_{\mathrm{e}}\left[\mathrm{cm}^{2} \mathrm{~V}^{-1} \mathrm{~s}^{-1}\right]$ & $\begin{array}{c}\mathrm{V}_{\mathrm{TH}} \\
(\mathrm{V})\end{array}$ & $\mathrm{I}_{\mathrm{ON}} / \mathrm{I}_{\mathrm{OFF}}$ & $\mu_{\mathrm{h}}\left[\mathrm{cm}^{2} \mathrm{~V}^{-1} \mathrm{~s}^{-1}\right]$ & $\mathrm{V}_{\mathrm{TH}}(\mathrm{V})$ & $\mathrm{I}_{\mathrm{ON}} / \mathrm{I}_{\mathrm{OFF}}$ \\
\hline NIPa3T & HMDS, $90^{\circ} \mathrm{C}$ & $5 \times 10^{-5}$ & -46 & $1 \times 10^{2}$ & & & \\
NIPa3T-DCV & OTS, $90^{\circ} \mathrm{C}$ & $2 \times 10^{-5}$ & 48 & $2 \times 10^{4}$ & & & \\
NIPa3T-DCV & HMDS, $90^{\circ} \mathrm{C}$ & $2 \times 10^{-5}$ & 54 & $2 \times 10^{6}$ & & & \\
NIPa3T-Rd & OTS, $90^{\circ} \mathrm{C}$ & $1 \times 10^{-4}$ & 47 & $3 \times 10^{4}$ & $1 \times 10^{-5}$ & -50 & $1 \times 10^{2}$ \\
NIPa3T-Rd & HMDS, $90^{\circ} \mathrm{C}$ & $1 \times 10^{-4}$ & 46 & $5 \times 10^{3}$ & $5 \times 10^{-6}$ & -15 & $3 \times 10^{1}$ \\
NIPa3T-Py & HMDS, $90^{\circ} \mathrm{C}$ & $4 \times 10^{-4}$ & 8 & $2 \times 10^{2}$ & & & \\
NIPa3T-Py & OTS, $90^{\circ} \mathrm{C}$ & $1 \times 10^{-2}$ & 42 & $9 \times 10^{2}$ & & & \\
NIPa3T-TIPS & HMDS $90^{\circ} \mathrm{C}$ & $4 \times 10^{-5}$ & -31 & $2 \times 10^{1}$ & & & \\
\hline
\end{tabular}

The field effect mobilities of the studied semiconductors are modest, with the maximum electron mobility of $10^{-2} \mathrm{~cm}^{2} \mathrm{~V}^{-1} \mathrm{~s}^{-1}$ for NIPa3T-Py (see selected output and transfer plots in Figure 7). 
From Table 4, it is noteworthy that NIPa3T-Rd is ambipolar, which can be related to its easiness to stabilize multiple positive and negative charges, as seen in the electrochemical study. However, the transistor parameters are quite modest. Nevertheless, an order of magnitude higher electron mobility is found for NIPa3T-Rd respect to NIPa3T-DCV, which can be related to the more extended $\pi$-conjugation as shown by Raman spectroscopy (Figure 3), to morphology effects as well as by the stronger electronwithdrawing ability of the rhodanine groups in comparison with the dicyanovinylene groups. As depicted in Figures S52 and S53, the rhodanine groups are able to stabilize a greater amount of negative charge upon electron injection.
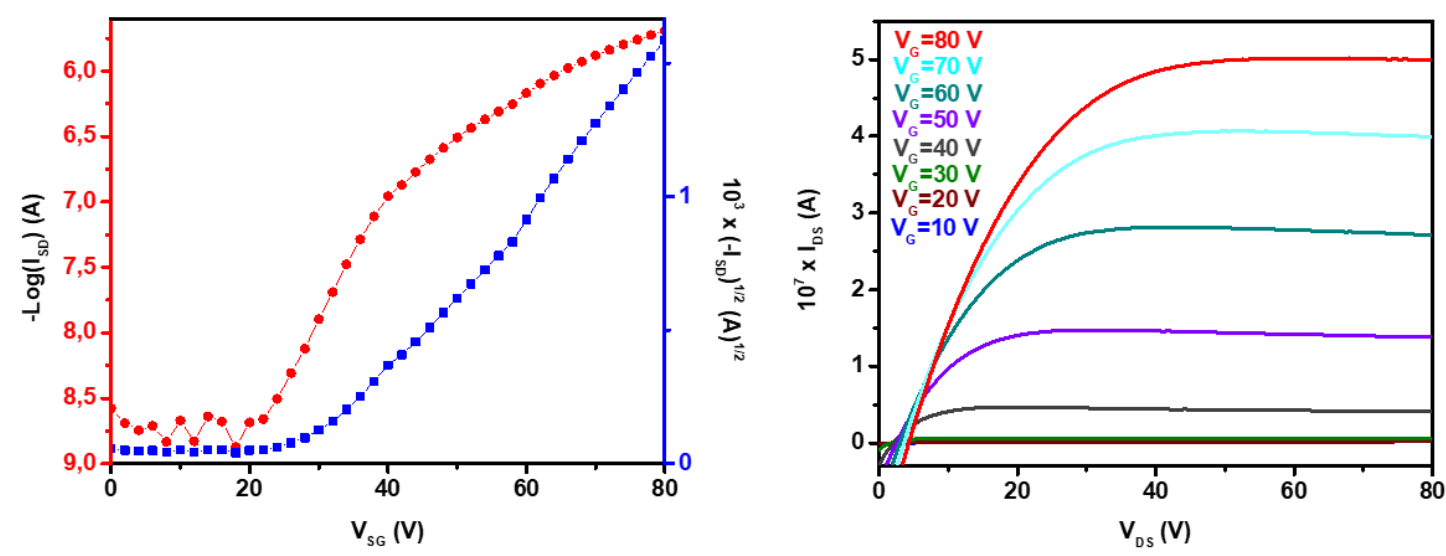

Figure 7. OFET transfer and output characteristics of NIPa3T-Py.

In addition, the two orders magnitude higher field effect mobility recorded for NIPa3TPy can be rationalized in terms of appropriate HOMO and LUMO levels and charge stabilization through the whole conjugated skeleton, since the pyrene units have been proved to also stabilize some of the injected charge (see Figures S52 and S53). Furthermore, close and cooperative $\pi-\pi$ interactions promoted by efficient interaction between the pyrene units improve the supramolecular aggregation of this derivative, as 
suggested by the crystallinity enhancement shown in XRD spectra (Figure S83) on going from NIPa3T to NIPa3T-Py.

\section{Organic photovoltaic proof of concept}

We have additionally made a first evaluation of the potential of this type of molecules as non-fullerene acceptors in organic solar cells. For this, a series of bulk heterojunction devices were fabricated in inverted structure, using for the active layer a blend of P3HT as the donor, and NIPb3T-Rd as acceptor. We chose NIPb3T-Rd due to its low band gap, leading to complementary absorption with P3HT, a factor that could potentially help to absorb a large fraction of the sun spectrum.

After optimizing the system with a High-throughput method (Figures S84, S85), the best performing sample contained $70 \%$ of P3HT and 30\% NIPb3T-Rd and yielded a $0.25 \%$ efficiency.

Table 5. P3HT:NIPb3T-Rd Organic Solar cell characterization.

\begin{tabular}{|ccccc|}
\hline \multicolumn{5}{|c|}{ Table 5. P3HT:NIPb3T-Rd Organic Solar cell characterization } \\
\hline D:A ratio & $\begin{array}{c}\text { Open circuit voltage } \\
\text { (V) }\end{array}$ & $\begin{array}{c}\text { Short circuit current } \\
(\mathrm{mA} / \mathrm{cm} 2)\end{array}$ & Fill Factor $(\%)$ & Efficiency (\%) \\
\hline $0.7: 0.3$ & 0.42 & 1.5 & 40 & 0.25 \\
\hline
\end{tabular}

Figure 9 shows that, despite the low efficiency values, the solar cell functions correctly and can act as a working p-n junction. Performance, however, is very limited. We believe that the relatively low efficiency values are due to several reasons. On the one hand, the modest charge mobility, in comparison with other non-fullerene acceptors (Table 4), strongly affects the fill factor and possibly introduces large recombination rates (seen here as a low $\mathrm{V}_{\mathrm{oc}}$ ). On the other hand, the explored materials have broadband absorption, which is positive to harvest as much as possible of the solar spectrum. Unfortunately, the oscillator strength is very small, leading to extinction coefficients (see Fig. 8 and Table 1 for the dipole moment) around one order of magnitude lower than typical conjugated polymers and NFAs. ${ }^{71,72}$ Effectively, this strongly affects the capability to absorb light in thin films based on this material, yielding small photocurrents. Moreover, the strong tendency observed for this molecule to phase separate from the polymer is believed to also reduce the charge generation capability of the system due to typically small exciton 
diffusion lengths observed in organic materials, further contributing to the limited measured photocurrent.

Although the device might have limited use as organic solar cell, the broadband absorption of NIPb3T-Rd might be interesting in the fabrication of photodetectors, where the thicker films would increase the absorption, and the moderate mobilities would be compensated by the driving voltage. Further experiments are being carried out in this direction and will be the subject of a future publication.

(a)

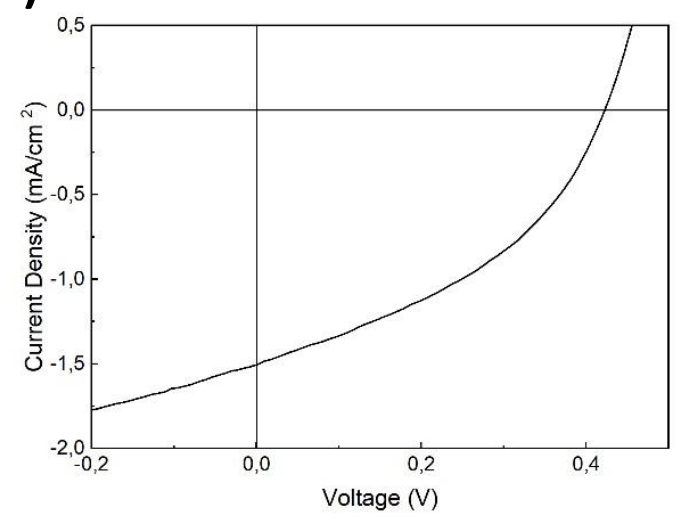

(b)

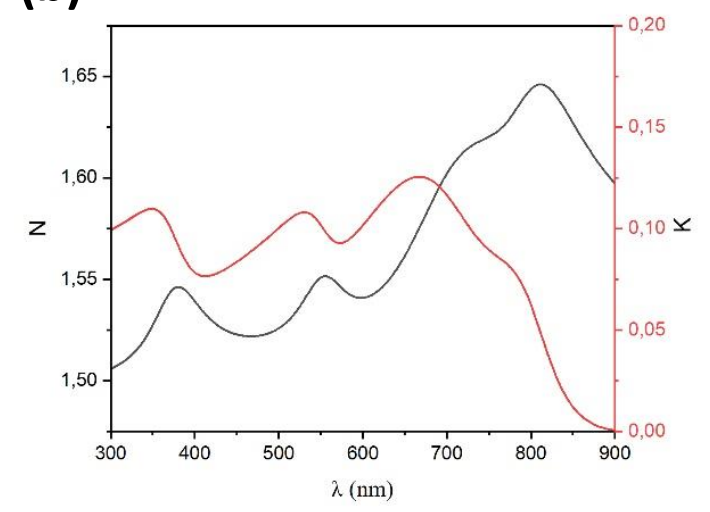

Figure 8. a) JV curve for the best performing P3HT:NIPb3T-Rd based solar cell. b) Complex refractive index ( $\mathrm{N}$ and $\mathrm{K})$ for thin film NIPb3T-Rd.

\section{Summary and conclusions}

A series of naphthalimide fused thienopyrazine derivatives laterally substituted by different donor and acceptor constituents has been synthesized, aiming to design molecules in which the energy and topology of the frontier molecular orbitals involved in the charge transport mechanism could be modulated. This set of materials allows, by both a theoretical and experimental approach, to analyze the effects on charge stabilization and charge transport of oligothiophene-napahthalimide assemblies by introducing additional electron donor or electron acceptor substituents at the terminal positions of the oligothiophene moieties. 
The molecular, optical and electronic properties have been thoroughly analyzed by DFT calculations, electrochemical measurements, optical and vibrational Raman spectroscopies and spectroelectrochemical studies.

The molecular dipole moments of the novel assemblies have been calculated given that dipole moments and geometrical restrictions are known to influence solid state packing. Interestingly, for those derivatives with strong electron acceptor lateral substituents, the interplay between the electron withdrawing strengths of the electron-rich lateral groups and the NIP unit yield molecules with small dipole moments and a more stable parallel configuration of stacking is predicted.

In addition, spectroelectrochemistry has been used to analyze the structure and stability of the charge carriers involved in the electron transport process. It is observed that in the assemblies with electron-donor lateral substituents, the injected negative charge is mostly delocalized over the naphthaleneimide fragment while in the assemblies with lateral electron-withdrawing groups, these groups are the ones bearing the majority of the injected charge.

The best mobility value has been obtained for the assembly with pyrene substituents. In this sense, the lateral pyrene units have proven to help both in charge stabilization and supramolecular aggregation, probably due to the appearance of close and cooperative $\pi$ $\pi$ interactions between pyrene units of two stacked molecules. On the other hand, the derivative bearing the strong rhodamine moiety at terminal positions has an ambipolar behavior. This can be rationalized in terms of the strong electron-withdrawing ability of the rhodanine groups as well as because of the more effective conjugation extension shown in Raman spectroscopy by the insertion of these lateral substituents. 
Finally, although the materials have broadband absorptions, which is positive to harvest a large fraction of the solar spectrum, they have limited use as non-fullerene acceptor in organic solar cells due to low electronic transitions oscillator strengths. However, some of these assemblies are potential candidates to be used as photodetectors, where the thicker films would increase overall light absorption, and the lower mobilities would be compensated by the driving voltage.

\section{Author contribution statement}

Matías J. Alonso-Navarro: Investigation, Data curation, Visualization, Writing original draft, Writing - review \& editing.

Alexandra Harbuzaru: Investigation, Data curation, Visualization, Writing - original draft, Writing - review \& editing.

Paula de Echegaray: Investigation, Data curation, Visualization.

Iratxe Arrechea-Marcos: Investigation, Data curation, Visualization.

Albert-Harillo-Baños: Investigation, Data curation, Visualization.

Alejandro de la Peña : Investigation, Data curation, Visualization

M. Mar Ramos, Visualization, Writing - review \& editing

J. Teodomiro López Navarrete, Visualization, Writing - review \& editing Mariano Campoy-Quiles, Conceptualization, Investigation, Visualization, Supervision, Writing - review \& editing.

Rocío Ponce Ortiz, Conceptualization, Investigation, Visualization, Supervision, Writing - review \& editing, Funding acquisition, Project administration.

José L. Segura, Conceptualization, Investigation, Visualization, Supervision, Writing review \& editing, Funding acquisition, Project administration. 


\section{Conflicts of interest}

There are no conflicts to declare

\section{Acknowledgements}

This work was financially supported by MINECO (MAT2016-77608-C3-2-P), MICINN (PID2019-106268GB-C33) and the UCM (INV.GR.00.1819.10759). MJAN gratefully acknowledges Universidad Rey Juan Carlos for a predoctoral contract. University of Málaga acknowledges support from Junta de Andalucia (UMA18- FEDERJA-080). We also thank CIC NanoGune for technical support in OFET characterization measurements. 
6. References

\section{Uncategorized References}

1. M. Wang, P. Baek, A. Akbarinejad, D. Barker and J. Travas-Sejdic, J. Mater. Chem. C, 2019, 7, 5534-5552.

2. B. Xie, Z. Chen, L. Ying, F. Huang and Y. Cao, InfoMat, 2019, 2, 57-91.

3. $\quad$ E. K. Lee, M. Y. Lee, C. H. Park, H. R. Lee and J. H. Oh, Adv Mater, 2017, 29.

4. Y. Jiang, Y. Guo and Y. Liu, Advanced Electronic Materials, 2017, 3.

5. D. Shi, Z. Liu, J. Ma, Z. Zhao, L. Tan, G. Lin, J. Tian, X. Zhang, G. Zhang and D. Zhang, Advanced Functional Materials, 2020, DOI: 10.1002/adfm.201910235.

6. M. Al-Hashimi, Y. Han, J. Smith, H. S. Bazzi, S. Y. A. Alqaradawi, S. E. Watkins, T. D. Anthopoulos and M. Heeney, Chemical Science, 2016, 7, 1093-1099.

7. J. Sun, Z. Liu, H. Luo, S. Yang, J. Yao, G. Zhang and D. Zhang, J. Mater. Chem. C, 2016, 4, 9359-9365.

8. Y. Wang, H. Guo, A. Harbuzaru, M. A. Uddin, I. Arrechea-Marcos, S. Ling, J. Yu, Y. Tang, H. Sun, J. T. López Navarrete, R. P. Ortiz, H. Y. Woo and X. Guo, J. Am. Chem. Soc., 2018, 140, 6095-6108.

9. S. Izumi, H. F. Higginbotham, A. Nyga, P. Stachelek, N. Tohnai, P. d. Silva, P. Data, Y. Takeda and S. Minakata, J. Am. Chem. Soc., 2020, 142, 1482-1491.

10. C. Poriel and J. Rault-Berthelot, J. Mater. Chem. C, 2017, 5, 3869-3897.

11. B. Kan, X. Chen, K. Gao, M. Zhang, F. Lin, X. Peng, F. Liu and A. K. Y. Jen, Nano Energy, $2020,67$.

12. J. Li, Y. Zhao, H. S. Tan, Y. Guo, C.-A. Di, G. Yu, Y. Liu, M. Lin, S. H. Lim, Y. Zhou, H. Su and B. S. Ong, Sci Rep, 2012, 2, 754.

13. I. Kang, H. J. Yun, D. S. Chung, S. K. Kwon and Y. H. Kim, J Am Chem Soc, 2013, 135, 14896-14899.

14. G. Kim, S. J. Kang, G. K. Dutta, Y. K. Han, T. J. Shin, Y. Y. Noh and C. Yang, J Am Chem Soc, 2014, 136, 9477-9483.

15. Y.-Q. Zheng, T. Lei, J.-H. Dou, X. Xia, J.-Y. Wang, C.-J. Liu and J. Pei, $A d v$. Mater., 2016, 28, 7213-7219.

16. J. Liu, J. Liu, J. Zhang, C. Li, Q. Cui, F. Teng, H. Li and L. Jiang, J. Mater. Chem. C, 2020, 8, 4303-4308.

17. J. T. E. Quinn, J. Zhu, X. Li, J. Wang and Y. Li, J. Mater. Chem. C, 2017, 5, 8654-8681.

18. H. Bronstein, C. B. Nielsen, B. C. Schroeder and I. McCulloch, Nat Rev Chem, 2020, 4, 66-77.

19. A. P. Dhondge, P. C. Tsai, C. Y. Nien, W. Y. Xu, P. M. Chen, Y. H. Hsu, K. W. Li, F. M. Yen, S. L. Tseng, Y. C. Chang, H. J. H. Chen and M. Y. Kuo, Org Lett, 2018, 20, 2538-2542.

20. A.-J. Payne, N. A. Rice, S. M. McAfee, S. Li, P. Josse, C. Cabanetos, C. Risko, B. H. Lessard and G. C. Welch, ACS Appl. Energy Mater., 2018, 1, 4906-4916.

21. Y. Peng and Z. Li, Mater. Chem. Phys, 2018, 214, 260-264.

22. S. Vasimalla, N. V. V. Subbarao, M. Gedda, D. K. Goswami and P. K. Iyer, ACS Omega, 2017, 2, 2552-2560.

23. Z. Zhao, S. Gao, X. Zheng, P. Zhang, W. Wu, R. T. K. Kwok, Y. Xiong, N. L. C. Leung, Y. Chen, X. Gao, J. W. Y. Lam and B. Z. Tang, Adv. Funct. Mater., 2018, 28, 1705609.

24. A. Nowak-Krol, K. Shoyama, M. Stolte and F. Wurthner, Chem Commun (Camb), 2018, 54, 13763-13772. 
25. S. Kumar, J. Shukla, Y. Kumar and P. Mukhopadhyay, Org. Chem. Front., 2018, 5, 2254-2276.

26. X. Zhan, A. Facchetti, S. Barlow, T. J. Marks, M. A. Ratner, M. R. Wasielewski and S. R. Marder, Adv. Mater., 2011, 23, 268-284.

27. P. Mayorga Burrezo, W. Zeng, M. Moos, M. Holzapfel, S. Canola, F. Negri, C. Rovira, J. Veciana, H. Phan, J. Wu, C. Lambert and J. Casado, Angew. Chem. Int. Ed., 2019, 58, 14467-14471.

28. J. Shukla and P. Mukhopadhyay, Eur. J. Org. Chem., 2019, 2019, 7770-7786.

29. M. A. Kobaisi, S. V. Bhosale, K. Latham, A. M. Raynor and S. V. Bhosale, Chem Rev, 2016, 116, 11685-11796.

30. M. J. Sung, A. Luzio, W.-T. Park, R. Kim, E. Gann, F. Maddalena, G. Pace, Y. Xu, D. Natali, C. de Falco, L. Dang, C. R. McNeill, M. Caironi, Y.-Y. Noh and Y.-H. Kim, Adv. Funct. Mater., 2016, 26, 4984-4997.

31. T. He, M. Stolte, C. Burschka, N. H. Hansen, T. Musiol, D. Kalblein, J. Pflaum, X. Tao, J. Brill and F. Wurthner, Nat Commun, 2015, 6, 5954.

32. R. P. Ortiz, H. Herrera, R. Blanco, H. Huang, A. Facchetti, T. J. Marks, Y. Zheng and J. L. Segura, J. Am. Chem. Soc., 2010, 132, 8440-8452.

33. A. Riaño Carnerero, G. López Espejo, M. J. Mancheño Real, B. Eckstein, R. C. González-Cano, F. S. Melkonyan, A. Facchetti, T. J. Marks, J. Casado, J. T. López Navarrete, J. L. Segura and R. Ponce Ortiz, J. Mater. Chem. C, 2017, 5, 9439-9450. 34. A. de la Pena, I. Arrechea-Marcos, M. J. Mancheno, M. C. Ruiz Delgado, J. T. Lopez Navarrete, J. L. Segura and R. Ponce Ortiz, Chemistry, 2016, 22, 13643-13652. 35. I. Arrechea-Marcos, P. de Echegaray, M. J. Mancheno, M. C. Ruiz Delgado, M. M. Ramos, J. A. Quintana, J. M. Villalvilla, M. A. Diaz-Garcia, J. T. Lopez Navarrete, R. Ponce Ortiz and J. L. Segura, Phys Chem Chem Phys, 2017, 19, 6206-6215.

36. J. Wang, K. Liu, L. Ma and X. Zhan, Chem Rev, 2016, 116, 14675-14725.

37. R. Dheepika, S. Sonalin, P. M. Imran and S. Nagarajan, J. Mater. Chem. C, 2018, 6, 6916-6919.

38. S. Hüttner, M. Sommer, U. Steiner and M. Thelakkat, Appl. Phys. Lett., 2010, 96, 073503.

39. K. Oniwa, H. Kikuchi, H. Shimotani, S. Ikeda, N. Asao, Y. Yamamoto, K. Tanigaki and T. Jin, Chem. Commun., 2016, 52, 4800-4803.

40. X. Gong, C. Zheng, X. Feng, Y. Huan, J. Li, M. Yi, Z. Fu, W. Huang and D. Gao, Chem Asian J, 2018, 13, 3920-3927.

41. S. Y. Liu, W. Q. Liu, J. Q. Xu, C. C. Fan, W. F. Fu, J. Ling, J. Y. Wu, M. M. Shi, A. K. Jen and H. Z. Chen, ACS Appl Mater Interfaces, 2014, 6, 6765-6775.

42. L. Wang, H. Liu, Z. Huai and S. Yang, ACS Appl Mater Interfaces, 2017, 9, 28828-28837.

43. M. Chen, L. Yan, Y. Zhao, I. Murtaza, H. Meng and W. Huang, J. Mater. Chem. C, 2018, 6, 7416-7444.

44. X. Yan, H. Fan, H. Gu, J. Zhang, X. Huang, R. Zhang and X. Zhan, Dyes and Pigments, 2015, 114, 124-128.

45. M. Privado, V. Cuesta, P. de la Cruz, M. L. Keshtov, R. Singhal, G. D. Sharmad and F. Langa, ACS Appl Mater Interfaces, 2017, 9, 11739-11748.

46. S. Badgujar, C. E. Song, S. Oh, W. S. Shin, S.-J. Moon, J.-C. Lee, I. H. Jung and S. K. Lee, J. Mater. Chem. A, 2016, 4, 16335-16340.

47. Y. Kim, C. E. Song, S. J. Moon and E. Lim, Chem Commun (Camb), 2014, 50, 8235-8238.

48. H. Z. C. Koerner, R. Fitzner, M. Riede, A. Mishra, P. Bäuerle, K. Leo, Advances in Polymer Science, Springer, Cham, 2017, 272. 
49. K. Wang, Y. Firdaus, M. Babics, F. Cruciani, Q. Saleem, A. El Labban, M. A. Alamoudi, T. Marszalek, W. Pisula, F. Laquai and P. M. Beaujuge, Chem. Mater., 2016, 28, 2200-2208.

50. J. Wu, Y. Ma, N. Wu, Y. Lin, J. Lin, L. Wang and C.-Q. Ma, Org. Electron., 2015, 23, 28-38.

51. M.-H. Yoon, S. A. DiBenedetto, A. Facchetti and T. J. Marks, J. Am. Chem. Soc., 2005, 127, 1348-1349.

52. J.-i. N. Shinji Ando, Hirokazu Tada, Youji Inoue, Shizuo Tokito, and Yoshiro Yamashita, J Am Chem Soc, 2005, 127, 5336-5337.

53. N. Sakai, J. Mareda, E. Vauthey and S. Matile, Chem Commun (Camb), 2010, 46, 4225-4237.

54. N. Zheng, Z. Lin, Y. Zheng, D. Li, J. Yang, W. Zhang, L. Wang and G. Yu, Org. Electron., 2020, 81, 105684.

55. C. Xiao, C. Li, F. Liu, L. Zhang and W. Li, J. Mater. Chem. C, 2020, 8, 53705374.

56. G. Liu, C. Xiao, F. Negri, Y. Li and Z. Wang, Angew Chem Int Ed Engl, 2020, 59, 2008-2012.

57. J. Lee, E.-S. Shin, Y.-J. Kim, Y.-Y. Noh and C. Yang, J. Mater. Chem. C, 2020, 8, 296-302.

58. J. L. Segura, H. Herrera and P. Bäuerle, J. Mater. Chem., 2012, 22, 8717-8733.

59. S. L. Suraru and F. Wurthner, Angew Chem Int Ed Engl, 2014, 53, 7428-7448.

60. R. P. Ortiz, H. Herrera, C. Seoane, J. L. Segura, A. Facchetti and T. J. Marks, Chemistry, 2012, 18, 532-543.

61. R. Ponce Ortiz, H. Herrera, M. J. Mancheno, C. Seoane, J. L. Segura, P. Mayorga Burrezo, J. Casado, J. T. Lopez Navarrete, A. Facchetti and T. J. Marks, Chemistry, 2013, 19, 12458-12467.

62. H. Herrera, P. de Echegaray, M. Urdanpilleta, M. J. Mancheno, E. MenaOsteritz, P. Bauerle and J. L. Segura, Chem Commun (Camb), 2013, 49, 713-715.

63. A. Riaño, P. Mayorga Burrezo, M. J. Mancheño, A. Timalsina, J. Smith, A. Facchetti, T. J. Marks, J. T. López Navarrete, J. L. Segura, J. Casado and R. Ponce Ortiz, J. Mater. Chem. C, 2014, 2, 6376-6386.

64. C. Castiglioni, J. T. Lopez Navarrete, G. Zerbi and M. Gussoni, Solid State Communications, 1988, 65, 625-630.

65. G. Zerbi, M. Veronelli, S. Martina, A.-D. Schlüter and G. Wegner, Adv. Mater., 1994, 6, 385-388.

66. J. Albero, P. Atienzar, A. Corma and H. Garcia, Chem. Rec., 2015, 15, 803-828.

67. S. R. González, J. Casado, J. T. L. Navarrete, R. Blanco and J. L. Segura, J. Phys. Chem. A, 2008, 112, 6732-6740.

68. S. Grimme, J. Comput. Chem., 2004, 25, 1463-1473.

69. S. Guha, F. S. Goodson, L. J. Corson and S. Saha, J. Am. Chem. Soc., 2012, 134, 13679-13691.

70. D. Branowska, E. Olender, W. Wysocki, Z. Karczmarzyk, I. Bancerz, P. Ledwon, M. Lapkowski, B. Mirosław, Z. Urbańczyk-Lipkowska and P. Kalicki, Electrochim. Acta, 2016, 214, 19-30.

71. A. Harillo-Baños, X. Rodríguez-Martínez and M. Campoy-Quiles, Adv. Energy Mater., 2020, 10, 1902417.

72. M. S. Vezie, S. Few, I. Meager, G. Pieridou, B. Dörling, R. S. Ashraf, A. R. Goñi, H. Bronstein, I. McCulloch, S. C. Hayes, M. Campoy-Quiles and J. Nelson, Nature Mater, 2016, 15, 746-753. 